\title{
A comparative analysis of UPFC as a Power Flow controller with applications
}

\author{
Ch.Kiran Kumar, M.Sudheer Kumar, V.SriramBabu, S.Nagulmeera \\ Dept. of EEE, Vikas College of Engineering and Technology, JNTU Kakinada,India. \\ B.Tech student of Vikas College of Engineering and Technology, JNTU Kakinada,India. \\ B.Tech student of Vikas College of Engineering and Technology, JNTU Kakinada,India. \\ B.Tech student of Vikas College of Engineering and Technology, JNTU Kakinada,India.
}

\begin{abstract}
Flexible alternating current transmission systems (FACTS) technology opens up new opportunities for controlling power and enhancing the usable cap-acity of present, as well as new and upgraded lines. FACTS technology reveals up new opportunities for controlling power and enhancing the usable capacity of present, as well as new and upgraded lines. This project describes the real and reactive power flow control through a transmission line by placing the UPFC at the sending end of an electrical power transmission system. The Unified Power Flow Controller (UPFC) is a second generation FACTS device which enables independent control of active and reactive power besides improving reliability and quality of the supply. The power flow control performance of the UPFC is compared with that of the other FACTS device called Static Synchronous Series Compensator(SSSC),TCSC,STATCOM Simulations are carried out in Matlab/Simulink environment to validate the performance of the UPFC.Finally, an introduction to the basic circuits of several FACTS controllers was provided with a focus on their system performance characteristics. In addition, some of the utility experience, real-world installations, and semiconductor technology development have been reviewed and summarized. TCSC provide reactive power control on transmission lines. In this respect, UPFC has the advantage over TCSC and phase shifter that it can control not only real power but also reactive power flow on transmission lines simultaneouslyIndex Terms - Flexible AC transmission systems (FACTS), FACTS Controllers, Power flow, Real and reactive power, SSSC, TCSC, Unified power flow controller (UPFC).
\end{abstract}

\section{Introduction}

The main objective of the power system operation is to match supply/demand, provide compensation for transmission loss, voltage and frequency regulation, reliability provision etc. The need for more efficient and fast responding electrical systems has given rise to innovative technologies in transmission using solid-state devices. These are called FACTS devices which enhance stability and increase line loadings closer to thermal limits.Flexible AC transmission systems (FACTS) have gained a great interest during the last few years, due to recent advances in power electronics. FACTS devices have been mainly used for solving various power system steady state control problems such as voltage regulation, power

$$
\begin{array}{llr}
\text { flow control, and transfer } & \text { capability } \\
\text { enhancement. The development of power }
\end{array}
$$

semiconductor devices with turn-off capability (GTO, MCT) opens up new perspectives in the development of FACTS devices. FACTS devices are the key to produce electrical energy economically and environmental friendly in future. The latter approach has two inherent advantages over the more conventional switched capacitor- and reactor- based compensators. Firstly, the power electronics-based voltage sources can internally generate and absorb reactive power without the use of ac capacitors or reactors. Secondly, they can facilitate both reactive and real power compensation and thereby can provide independent control for real and reactive power flow. Its main objectives are to increase power transmission capability, voltage control, voltage stability enhancement and power system stability improvement. Its first concept was introduced by N.G.Hingorani[2] in April 19, 1988. Since then different kind of FACTS controllers have been recommended. FACTS controllers are based on voltage source converters and includes devices such as Static Var Compensators (SVC), static Synchronous Compensators (STATCOM), Thyristor Controlled Series Compensators (TCSC), Static

Synchronous Series Compensators (SSSC) and Unified Power Flow Controllers (UPFC)[2].Among them UPFC is the most versatile and efficient device which was introduced in 1991. In UPFC, the transmitted power can be controlled by changing three parameters namely transmission magnitude voltage, impedence and phase angle. 


\section{Unified Power Flow Controll}

Combining the STATCOM and the SSSC into a single device with a common control system represents the third generation of FACTS known as Unified Power Flow Controller (UPFC). It has the unique ability to control real and reactive power flow independently. The first utility demonstration of a UPFC is being constructed at the Inez substation of American Electric Power in 1998 [6]. Recently, 80 MVA UPFC is being constructed at Gangjin substation in South Korea. Table 3 shows the details of UPFCs installed in two locations.

\subsection{OPERATION OF UPFC}

Inverter 2 provides the main function of the UPFC by injecting an ac voltage Vpq with controllable magnitude Vpq (0 $\square \mathrm{Vpq} \square$ Vpqmax) and phase angle $\square(0 \square \square \square 360)$, at the power frequency, in series with the line via an insertion transformer. The injected voltage is considered essentially as a synchronous voltage source. The transmission line current flows through this voltage source resulting in real and reactive power exchange between it and the ac system. The real power exchanged at the ac terminal (i.e., at the terminal of insertion transformer) is converted by the inverter into dc power that appears at the dc link as positive or negative real power demanded. The reactive power exchanged at the ac terminal is generated internally by the inverter.

Operation of the UPFC from the standpoint of conventional power transmission based on reactive shunt compensation, series compensation, and phase shifting, the UPFC can fulfill thesefunctions and therebymeet multiple control objectives by adding the injected voltage Vpq, with appropriate amplitude and phase angle, to the terminal voltage Vo. Using phasor representation,

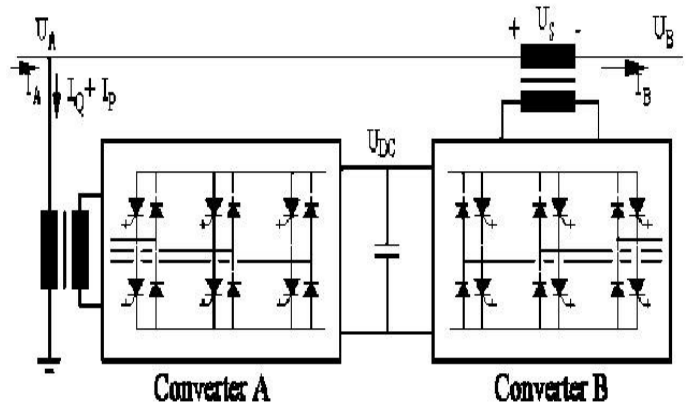

Figure: Basic circuit arrangement of unified power flow controller

The basic function of Inverter 1 is to supply or absorb the real power demanded by Inverter 2 at the common dc link [1]. This dc link power is converted back to ac and coupled to the transmission line via a shuntconnected transformer. Inverter 1 can also generate or absorb controllable reactive power, if it is desired, and there by it can provide independent shunt reactive compensation for the line. It is important to note that where as there is a closed "direct" path for the real power negotiated by the action of series voltage injection through Inverters 1 and 2 back to the line, the corresponding reactive power exchanged is supplied or absorbed locally by inverter 2 and therefore it does not flow through the line. Thus, inverter 1 can be operated at a unity power factor or be controlled to have a reactive power exchange with the line independently of the reactive power exchanged by the by the Inverter 2 . This means there is no continuous reactive power flow through UPFC.

\section{Basic control functions:}

the basic UPFC power flow control functions are illustrated in Figure.2. Terminal voltage regulation, similar to that obtainable with a transformer tap-changer having infinitely small steps, as shown at (a) where $\mathrm{Vpq}=\square \mathrm{V}$ (boldface letters represent phasors) is injected in-phase (or anti-phase) with Vo [ 4 ].

Series capacitor compensation, is shown at

(b) where $\mathrm{Vpq}=\mathrm{Vc}$ is in quadrate with the line current $I$. Transmission angle regulation, (phase shifting) is shown at (c) where $\mathrm{Vpq}=\mathrm{Vo}_{0}$ is injected with angular relationship with respect to Vo that 

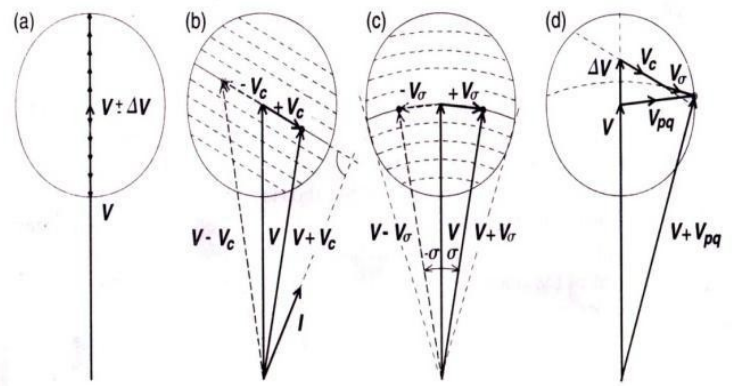

Figure- Basic UPFC Control Functions Figure (a) - Voltage regulation

Figure (b) - Line impedance compensation Figure (c) - Phase shifting

Figure (d) - Simultaneous control of voltage, impedance, and angle

Multifunction power flow control, executed by simultaneous terminal voltage regulation, series capacitive compensation, and phase shifting, is shown at (d) where $\mathrm{Vpq}=\square \mathrm{V}+\mathrm{Vc}+\mathrm{Vo}$.

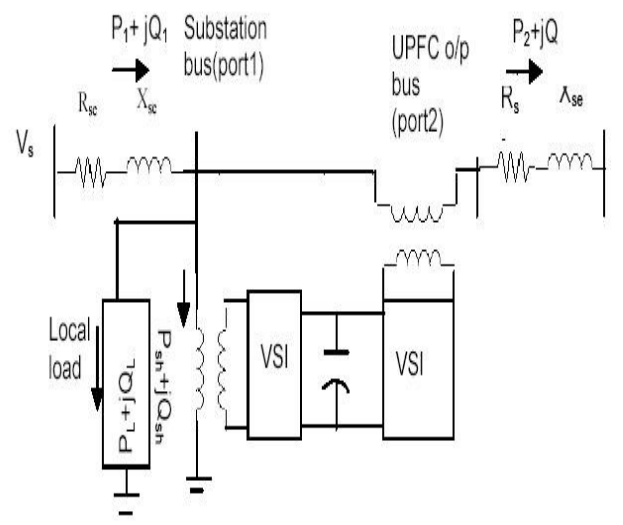

achieves the desired s phase shift (advance or retard) with out any change in magnitude.

Specifications of the system taken for testing the

control strategy are:

$\mathrm{Xse}=0.075, \mathrm{Rse}=0.0075, \mathrm{Xsh}=0.15, \mathrm{Rsh}=0.01$, gcap $=0.02$, bcap $=2 . \mathrm{Vr}=10$, Load 3p.u with p.f.0.8 (lag) All the above quantities are on the UPFC MVA base (33.33 MVA), which is assumed to be $1 / 3$ rd of the transmission line MVA base.

The proposed control strategy was tested for the following cases:

Case(i) $: \mathrm{Vs}=10$, initially shunt control is OFF, shunt control on at $\mathrm{T}=0.04 \mathrm{~s}$, Pref $=0$, load switch on at $\mathrm{t}=0.08 \mathrm{sec}$, at $\mathrm{t}=0.25 \mathrm{~s}$ load throughout and subsequently shunt control OFF.

\subsection{Modeling of UPFC :}

The control system described in the previous chapter was derived by assuming that the series and parallel converters are treated as ideal controllable voltage sources, that the values of the fundamental components of the line currents are locally available. The UPFC is modeled by combining the shunt and series branches coupled by the DC voltage control branch.Local load is added at port 1 of the UPFC. The Organization of UPFC modeling blocks are shown in below figure. 
Figure:UPFC test system

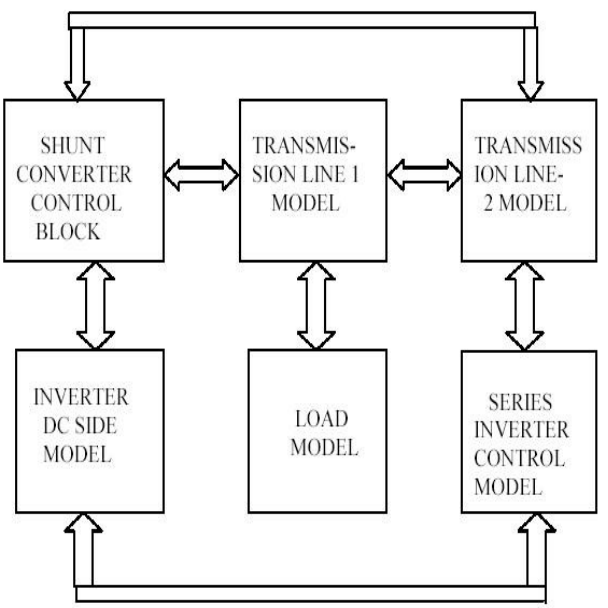

Figure : Organization of UPFC modeling blocks

\subsection{Generation,Transmission,Distribution}

\section{Control Of Power Systems}

When discussing the creation, movement, and consumption of electrical power, it can be separated into three areas, which traditionally determined the way in which electric utility companies had been organized.These are illustrated as;

\section{Generation \\ Transmission \\ Distribution}

\subsection{Power System Constraints}

As noted in the introduction, transmission systems are being pushed closer to their stability and thermal limits while the focus on the quality of power delivered is greater than ever. The limitations of the transmission system can take many forms and may involve power transfer between areas (referred to here as transmission bottlenecks) or within a single area or region (referred to here as a regional constraint) and may include one or more of the following characteristics:

- Voltage Stability Limit

- Dynamic Voltage Limit

- Steady-State Power Transfer Limit

- Transient Stability Limit

- Short-Circuit Current Limit

- Power System Oscillation Damping Limit

- Thermal Limit

- Short-Circuit Current Limit

Each transmission bottleneck or regional constraint may have one or more of these system-level problems.

3.3 Controllability of Power Systems To illustrate that the power system only has certain variablesthatcanbeimpactedbycontrol,considerthebasa nd well-known power-angle curve,shown.Although this is a steady-state curve and the implementation of FACTS is primarily for dynamic issues, this illustration demonstrates the point that there are primarily three main variables that can be directly controlled in the power system $[4,5]$ to impact its performance. These are:

- Voltage

- Angle

- Impedance

With the establishment of "what" variables can be controlled in a power system, the next question is "how" these variables can be controlled. The answer is presented in two parts: namely conventional equipment and FACTS controllers[6]. Some of the examples of Conventional Equipment For Enhancing Power System Control 
like,Transformer LTC, Switched Shunt-Capacitor and Reactor, Synchronous Condenser etc, which Controls voltage. Phase Shifting Transformer, and Series Capacitor which Controls angle and impedance respectively. Special Stability Controls, Typically focuses on voltage control but can often include direct control of power. Some of the examples of FACTS Controllers for Enhancing Power System Control are Thyristo Controlled Series Compensator (TCSC), which Controls Impedance. Static Var Compensator (SVC) which Controls Voltage.Static Synchronous

Power Flow Controller (IPFC) Each of the aforementioned (and similar) controllers impact voltage, impedance, and/or angle (\& power)) Thyristor Controlled Phase Shifting Transformer (TCPST) which Controls angle.

\title{
3.4 Benefits of Control of Power Systems
}

Once power system constraints are identified and through system studies viable solutions options are identified, the benefits of the added power system control must be determined. The following offers a list of such benefits.

\author{
Improved Power System Stability \\ Increased System Reliability \\ Increased System Security \\ Increased Loading and More Effective Use of Transmission Corridors \\ Added Flexibility in Siting New Generation
}

The advantages in this list are important to achieve in the overall planning and operation of power systems. However, for justifying the costs of implementing added power system control and for comparing conventional solutions to FACTS controllers, more specific metrics of the benefits to the power system are often required.

\section{Facts Applications}

FACTS controllers can be used for various applications to enhance power system performance. One of the greatest advantages of using FACTS controllers is that it can be used in all the three states of the power system, namely:

(1) Steady state,

(2) Transient

(3) Post transient steady state.

Compensator (STATCOM) which Controls Voltage. Static Synchronous Series Controller (SSSC), Unified Power Flow Controller (UPFC), Inter-phase

However, the conventional devices find little application during system transient or contingency condition.

\subsection{STEADY STATE APPLICATION}

Various steady state applications of FACTS controllers includes voltage control (low and high), increase of thermal loading, post-contingency voltage control, loop flows control, reduction in short circuit level and power flow control. SVC and STATCOM can be used for voltage control while TCSC is more suited for loop flow control and for powerflow control.

\subsection{CONGESTION MANAGEMENT}

Congestion management is a serious concern for Independent System Operator (ISO) in present deregulated electricity markets as it can arbitrarily increase the prices and hinders the free electricity trade. FACTS devices like TCSC, TCPAR (Thyristor Controlled Phase Angle Regulator) and UPFC can help to reduce congestion, smoothen locational marginal prices (LMP) and to increase the social welfare by redirecting power from congested interface to under utilised lines.

\subsection{ATC IMPROVEMENT}

In many deregulated market, the power transaction between buyer and seller is allowed based on calculation of ATC. Low ATC signifies that the network is unable to accommodate further transaction and hence does not promote free competition. FACTS controllers like TCSC, TCPAR and UPFC can help to improve ATC by allowing more power transactions.

\subsection{REACTIVE POWER AND VOLTAGE CONTROL}

The use of shunt FACTS controllers like SVC and STATCOM for reactive power and voltage control is well known. 


\subsection{LOADING MARGIN IMPROVEMENT}

Several blackouts in many part of the world occurs mainly due to voltage collapse at the maximumloadability point. Series and shunt compensations are generally used to increase the maximum transfer capabilities of power networks. The recent advancement in FACTS controllers have allowed them to be used more efficiently for increasing the loading margin in the system.

\subsection{POWER FLOW BALANCING AND CONTROL}

FACTS controllers, especially TCSC, SSSC and UPFC, enable the load flow on parallel circuits and different voltage levels to be optimized and controlled, with a minimum of power wheeling, the best possible utilization of the lines, and a minimizing of overall system losses at the same time.

\subsection{DYNAMIC APPLICATION}

Dynamic application of FACTS controllers includes transient stability improvement, oscillation damping (dynamic stability) and voltage stability enhancement. One of the most important capabilities expected of FACTS applications is to be able to reduce the impact of the primary disturbance. The impact reduction for contingencies can be achieved through dynamic voltage support (STATCOM), dynamic flow control (TCSC) or both with the use of UPFC.

\subsection{TRANSIENT STABILITY ENHANCEMENT}

Transient instability is caused by large disturbances such as tripping of a major transmission line or a generator and the problem can be seen from the first swing of the angle. FACTS devices can resolve the problem by providing fast and rapid response during the first swing to control voltage and power flow in the system.

\subsection{OSCILLATION DAMPING}

Electromechanical oscillations have been observed in many power systems worldwide and may lead to partial power interruption if not controlled. Initially, power system stabilizer (PSS) is used for oscillation damping in power system. Now this function can be more effectively handled by proper placement and setting of SVC, STATCOM and TCSC.

\subsection{DYNAMIC VOLTAGE CONTROL}

Shunt FACTS controllers like SVC and STATCOM as well as UPFC can be utilized for dynamic control of voltage during system contingency and save the system from voltage collapse and blackout.

\subsection{POWER SYSTEM INTERCONNECTION}

Interconnection of power systems is becoming increasingly widespread as part of power exchange between countries as well as regions within countries in many parts of the world. There are numerous examples of interconnection of remotely separated regions within one country. Such are found in the Nordic countries, Argentina and Brazil. In cases of long distance AC transmission, as in interconnected power systems, care has to be taken for safeguarding of synchronism as well as stable system voltages, particularly in conjunction with system faults. With series compensation, bulk AC power transmission over distances of more than $1,000 \mathrm{~km}$ are a reality today and hasbeen used in Brazil north- south interconnection. With the advent of TCSC, further potential as well as flexibility is added to AC power transmission.

\subsection{APPLICATION IN DEREGULATED ENVIRONMENT}

Apart from its traditional application for voltage control, power flow control and enhancing steady state and dynamic limits, FACTS controllers are finding new applications in the present deregulated environment. One of the applications is in controlling the "parallel flow" or "loop flow". Loop flow results in involuntary reduction in transmission capacity that may belong to some other utility and hence foreclose beneficial transactions through that line. Utilities can also make use of FACTS controllers in their tie lines, either to shield it from the neighbouring effects, such as wheeling transactions or to participate in such transaction. FACTS devices can also be implemented to ensure the economy in operation by placing it in a suitable line such that least cost generators can be dispatched more. It can also be used to reduce the losses in the system. Yet, another application is to use FACTS to relieve the congestion in the system. FACTS devices can be strategically placed such that congestion cost is reduced, curtailment is decreased and price volatility due to congestion is minimized.

\section{Benefits And Costs}

The benefits from the use of FACTS devices are many, however, not all are tangible. Similarly, the cost of FACTS devices are also huge. The world second UPFC came into operation at the end of year 2004 in 
Keepco power system in Korea. It was the largest single procurement order ever placed by Keepco. From this, it is clear how expensive these technologies are. But, the cost has to computed against anticipated benefits. One of the reasons for low deployment of FACTS is because very little has been done to show their profitableness. FACTS devices can save the system from potential threat of system collapse, which can have very serious consequences on other economic sector as well. It can help to avoid the wide spread blackout. The opportunity cost of FACTS controllers in these situations has to taken into consideration.

\subsection{ENVIRONMENTAL BENEFIT}

The construction of new transmission line has negative impact on the environment. FACTS devices help to distribute the electrical energy more economically through better utilization of existing installation there by reducing the need for additional transmission lines. For example, in Sweden, eight $400 \mathrm{kV}$ systems run in parallel to transport electrical energy from the north to the south. Each of these transmission systems is equipped with FACTS.

Studies have shown that four additional $400 \mathrm{kV}$ transmission systems would be necessary, if FACTS were not utilized on the existing systems.

\subsection{INCREASED STABILITY}

Instabilities in power system are created due to long length of transmission lines, interconnected grid, changing system loads and line faults in the system. These instabilities results in reduced line flows or even line trip. FACTS devices stabilize transmission systems with increased transfer capability and reduced risk of line trips.

\subsection{INCREASED QUALITY OF SUPPLY}

Modern industries require high quality of electricity supply including constant voltage and frequency, and no supply interruptions. Voltage dips, frequency variations or the loss of supply can lead to interruptions in manufacturing processes with high economic losses. FACTS devices can help to provide the required quality of supply.

\subsection{FLEXIBILITY AND UPTIME}

Unlike new overhead transmission lines that take several years to construct, FACTS installation requires only 12 to 18 months. FACTS installation has the flexibility for future upgrades and requires small land area.

\subsection{FINANCIAL BENEFIT}

Financial benefit from FACTS devices comes from the additional sales due to increased transmission capability, additional wheeling charges due to increased transmission capability and due to delay in investment of high voltage transmission lines or even new power generation facilities. Also, in a deregulated market, the improved stability in a power system substantially reduces the risk for forced outages, thus reducing risks of cost revenue and penalties from power contracts.

\subsection{REDUCED MAINTENANCE COST}

The overhead transmission lines need to be cleared from the surrounding environment (e.g. tree branches) from time to time. In comparison to this, the FACTS maintenance cost is very minimum. In addition, as the number of transmission line increases, the probability of fault occurring in a line is also high. So, by utilizing the transmission systems optimally with the use of FACTS, the total number of line fault is minimized, thus reducing the maintenance costs.

\section{Costs}

As compared to conventional devices, FACTS controllers are very expensive. The approximate cost per kVar output of various conventional devices and FACTS controllers are shown in Table 4 [19]. However, the cost per kVar decreases for higher capacity of FACTS controllers. The total cost also depends on the size of fixed and controlled portion of the FACTS controllers. The FACTS equipment cost represent only half of the total FACTS project cost. Other costs like civil works, installation, commissioning, insurance, engineering and project management constitute the other half of the FACTS project cost. 


\section{Table : Cost of conventional and FACTS controllers}

\begin{tabular}{|c|c|}
\hline FACTS Controllers & Cost (US \$) \\
\hline Shunt Capacitor & $8 / \mathrm{kVar}$ \\
\hline Series Capacitor & 20/kVar \\
\hline $\mathrm{SVC}$ & $\begin{array}{l}40 / \mathrm{kVar} \text { controlled } \\
\text { portions }\end{array}$ \\
\hline TCSC & $\begin{array}{l}\text { 40/ } \mathrm{kVar} \text { controlled } \\
\text { portions }\end{array}$ \\
\hline STATCOM & $50 / \mathrm{kVar}$ \\
\hline UPFC Series Portions & 50/kVar through power \\
\hline UPFC Shunt Portions & $50 / \mathrm{kVar}$ controlled \\
\hline
\end{tabular}

\section{Simulation results and discussion}

Notations used to represent simulated waveforms are: $\mathrm{Ese}=$ Series inverter output voltage

Esh $=$ Shunt inverter output voltage

Eshrms $=$ RMS value of series converter output voltage

Eserms $=$ RMS value of series converter output voltage power flow from sending end to port1 measured at port1

$\mathrm{Q} 1=$ Reactive power flow from sending end to portl measured at port1

$\mathrm{P} 2=$ Real power flow from port $2 \mathrm{t}=\mathrm{R}$ o receiving end bus measured at port2

Q2=Reactive power flow from port2 to receiving end measured at port2

Psh $=$ Real power flow from port1 to shunt converter measured at port1

$\mathrm{Qsh}=$ Reactive power flow from port1 to shunt converter measured at port 1

$\mathrm{PL}=$ Real power flow from port1 to load measured at port1

$\mathrm{QL}=$ Reactive power flow from port1 to load measured at port1.

$\mathrm{Pse}=$ Real power flow from series converter to port2 measured at port2.

$\mathrm{Qse}=$ Reactive power flow from series converter to port2 measured at port2.

$\mathrm{VDC}=$ Voltage across $\mathrm{DC}$ capacitor $\mathrm{V} 1-\mathrm{A}=$ Port 1 phase-A voltage. $\mathrm{V} 2-\mathrm{A}=$ Port 2 phase-A voltage.

$\mathrm{V} 1 \mathrm{rms}=\mathrm{RMS}$ value of port 1 voltage $\mathrm{V} 2 \mathrm{rms}=\mathrm{RMS}$ value of port2 voltage.

In all the plots below $\mathrm{X}$-axis represents time in seconds.

Results of a P1eal sample simulation run using the model developed follow.

Study Case: Vs $=1 \square 0$, load 3p.u with lagging power factor 0.8 , initially shunt control is OFF, shunt control $\mathrm{ON}$ at $\mathrm{T}=0.04 \mathrm{sec}, \mathrm{P}_{\mathrm{Ref}}=0$, load switch on at $\mathrm{t}=0.08 \mathrm{sec}$. The plot of the simulation results shown in Figures below.

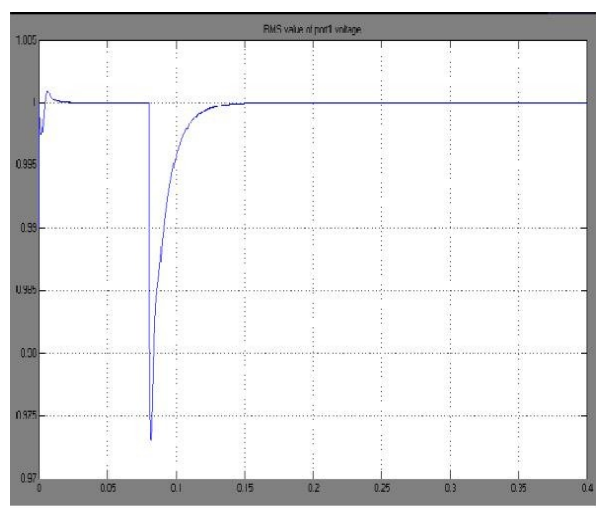

Figure: Simulation result of V1 Angle

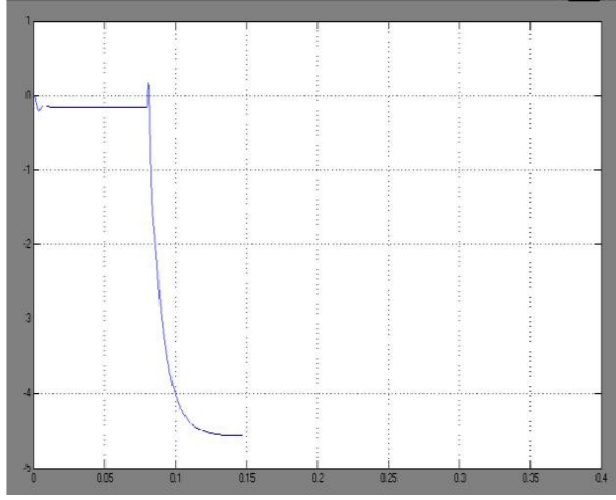

Figure: Simulation result of

$V_{1 \text { rms }}$ 


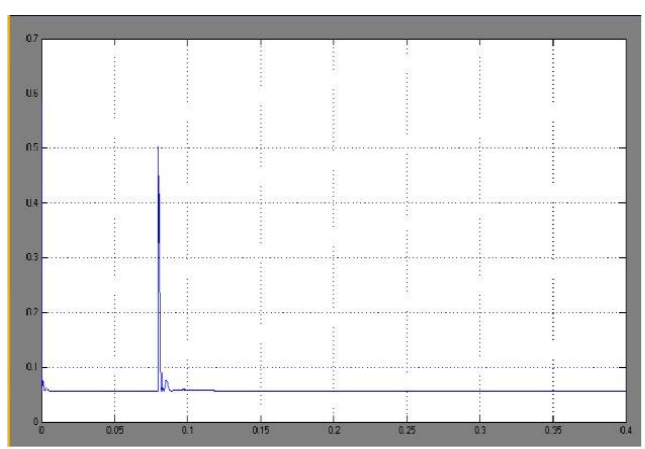

Figure: Simulation result of $\mathrm{V}_{2} \mathrm{rms}$

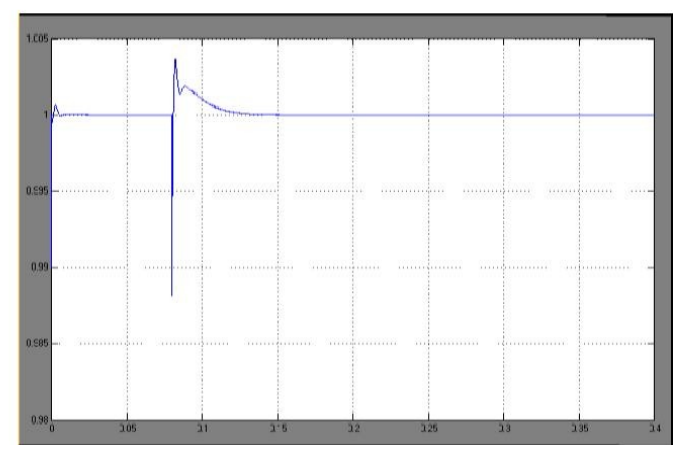

Figure:Simulation result of V2 angle

\section{ISSUES}

High cost and high losses, appropriate size and setting, location and procurement availability are some major issues with the use of FACTS controllers. Even with the long history of development, proven technology and long list of benefits, FACTS controllers are not yet widely deployed because of the high cost as compared to the conventional counterpart.

The procurement availability of FACTS controllers is also a major issue. Market for SVC is widely developed and can be procured competitively. While, very limited competition exists regarding the procurement of TCSC and STATCOM. For the case of UPFC, it is more likely that there will be no competition at all. Another important concern is the losses, which increase with higher loading and FACTS devices produce more loss than the conventional ones. So, more effort is needed in the development of semiconductor switches that are fast and, at the same time, have low switching and conduction losses. Size of FACTS controllers also bears significance, since cost increases proportionally with the size. Similarly appropriate setting and location are important to obtain the desired performance. These are to be addressed during the planning stage of the FACTS project. As the number of FACTS controllers increases in the power system, the interactions among the controllers itself will be a serious concern that requires separate in-depth study.

\section{Conclusion}

Finally, an introduction to the basic circuits of several FACTS controllers was provided with a focus on their system performance characteristics. The FACTS controllers clearly enhance power system performance, improve quality of supply and also provide an optimal utilization of the existing resources. It has been concluded that none of the existing FACTS devices namely, TCSC provide reactive power control on transmission lines. In this respect, UPFC has the advantage over TCSC and phase shifter that it can control not only real power but also reactive power flow on transmission lines simultaneously Future systems can be expected to operate at higher stress levels so the FACTS could provide means to control and alleviate stress. All these will hasten the broad application of the FACTS concepts and the achievement of its ultimate goal, the higher utilization of electric power systems.

\section{References}

[1]. N.G. Hingorani and L. Gyugyi "Understanding FACTS concepts and technology of flexible AC transmission systems",

[2]. IEEE Press, New York, 2000.

[3]. L. Gyugyi, "Unified power-flow control concept for flexible ac transmission systems", IEE Proceedings-C, Vol. 139, NO.4, pp:323-33 I , July 1992

[4]. John J. Paserba, Fellow, IEEE, “ How FACTS Controllers Benefit FACTS AC Transmission Systems”

[5]. P. Kundur, Power System Stability and Control, McGraw- Hill Inc., 1994, pp:813-816

[6]. Yong Hua Song and Allan T Johns, Flexible ac transmission system (FACTS), IEE power and energy series, 1999. S. Y. Ge T S Chung „Optimal active power flow incorporating power flow control needs in flexible ac transmission systems”

[7]. R. MihaliE and P. hnko, Member, D. Povh, Fellow IEEE "Improvement of transient stability using unified power flow controller $^{\mathrm{ee}}$

[8]. R.M. Mathur, R.K. Varma, 2002, "Thyristor-based FACTS Controllers for Electrical Transmission Systems," IEEE Press, Piscataway.

[9]. Preeti Singh, Mrs.Lini Mathew, Prof. S. Chatterji „MATLAB Based Simulation of TCSC FACTS Controller”

[10]. K.K. Sen, 1998, "SSSC - Static Synchronous Series Compensator: Theory, Modeling and Application”, IEEE Trans. onPower Delivery, 13(1), pp. 241-246.

[11]. SongpakitKaewniyompanit, YasunoriMitani and Kiichiro Tsuji "Optimal allocation and type selection of a power system stabilizing FACTS device in a multi-machine system by micro- GA"

[12]. Kannan. S, SheshaJayaram and M.M.A.Salama.(2007), Real and Reactive Power Coordination for a Unified Power Flow Controllere ${ }^{\text {Ie }}$ IEE Transactions on Power Systems, 2007, vol.19.No.3, pp. $1454-1461$. 